\title{
An Episodic Account of Divine Personhood
}

\author{
Justin Mooney \\ University of Massachusetts Amherst \\ jmooney@umass.edu
}

[A version of this article is forthcoming in Religious Studies 2020]

\section{Introduction}

There is a minority strand of Trinitarian thought that attempts to be orthodox while also affirming that the divine persons are numerically identical. ${ }^{1}$ Naturally, any view which identifies the divine persons with each other invites worries about modalism, with one author alleging that the idea is 'quite straightforwardly heretical'. ${ }^{2}$ But the minority insists that, though the Father, Son, and Spirit are numerically identical, none of them

\footnotetext{
${ }^{1}$ Perhaps the clearest case is Effingham (2015). Effingham claims to be following in the footsteps of Leftow (2004) on this point, but it's unclear whether he is right about that. On the one hand, Hasker (2013) - who has engaged with Leftow at length - also reads Leftow's model as entailing the identity of the divine persons. But Rea (2009a) reads him differently, and Leftow's (2007) later addition (modification?) to his model seems to vindicate Rea's interpretation. Either way, Leftow's work has at least suggested this way of thinking about the Trinity. (Thanks to a referee for pressing me on this in their comments on a different article.)

${ }^{2}$ Hasker (2013), 116; Hasker's worry is not idiosyncratic. Modalism, which claims that the divine persons are in fact merely modes of one and the same person, was officially rejected as a heresy by the early church. Prima facie, it is hard to see how one can claim that the divine persons are identical without thereby endorsing modalism. Relatedly, one might think that the doctrine of the divine processions entails that the persons are distinct (as, e.g., Augustine, De Trinitate Book I.2; thanks to a referee for this reference).
} 
is the same person as any of the others. The challenge is how to make sense of this position. ${ }^{3}$

Fortunately for fans of this minority view, I think there is a plausible metaphysics that can give them exactly what they want: Ned Markosian's (2008 \& 2010) episodic account of identity under a sortal. In this paper, I present Markosian's account, and use it to sketch a model of the Trinity. Then I show that the model can be used to solve at least three important Trinitarian puzzles: the traditional 'logical problem of the Trinity', which is about how three different persons can be one God; a less-discussed problem that has been dubbed the 'problem of triunity', which is about how each person of the Trinity can be God without being triune; and a problem about a tension between the divine processions and aseity, which has been enjoying increased attention in the recent literature.

\section{When People Outnumber Objects}

Ned Markosian's episodic account of identity under a sortal is inspired in part by the fact that there are possible situations in which people seem to outnumber objects. Consider the case which Markosian (2008) calls 'The Mummy's:

Once upon a time there was a man who lived a long and happy life. Then he died, and his body was preserved, as a mummy, for a million years. Eventually the mummy came to the attention of a powerful being, who gradually rearranged the particles that composed the mummy until they came to compose a living, breathing, human person who happened to be a woman and who

\footnotetext{
${ }^{3}$ Notice that this position differs from the 'simple trinitarianism' recently defended by Shieva Kleinshmidt (2016 \& 2018). While both views deny that the persons are to be identified with entities distinct from God, the view I aim to defend identifies them with God, whereas the simple trinitarian denies that they are in our ontology at all.

${ }^{4}$ A different version of the case appears in his (2010).
} 
had a psychology that was utterly different and discontinuous from the psychology of the man from the beginning of the story (17).

Markosian presents another version of this story in his (2010), and, taking into account his description and treatment of both cases, it's clear that Markosian is not imagining that the mummy is disassembled and then reassembled into a woman. Rather, the mummy's particles are rearranged without ever being disassembled in order to transform the Mummy into a woman, perhaps in something like the way one might mould a hunk of clay.

Markosian's interpretation of this case is that the man at the beginning of the story is the same object as the woman at the end of the story, but the man at the beginning of the story is not the same person as the woman at the end of the story (17). ${ }^{5} \mathrm{I}$ am inclined to agree. After all, at no point in this transformation would it appear to a bystander that any humanshaped object had gone in or out of existence rather than merely changing. ${ }^{6}$ By my lights, this is a strong reason to think that the woman is the same object as the man. And yet the woman at the end of the story is neither biologically nor psychologically continuous with - or even similar to - the man. ${ }^{7}$ Moreover, one might think that, intuitively, the woman ought not to be praised and blamed for the deeds performed by the man in his lifetime. By my lights, these are strong reasons to think that the woman is not the same person as the man.

But I don't have the space to defend Markosian's interpretation of The Mummy case in detail, and that is not the purpose of this paper. My

\footnotetext{
${ }^{5}$ In the service of developing a model of the Trinity, Effingham (2015) has also presented a case of this sort - an even more exotic one involving synchronic multilocation.

${ }^{6}$ This characterization of the Mummy case as involving mere change and not going in or out of existence is indebted to lecture notes where Markosian suggests that one could view death as merely changing rather than going out of existence. Cf. Olson (1997), chs. 2 and 4 on person as a phase sortal, in contrast to (e.g.) Baker (2000).

${ }^{7}$ Cf. Markosian's (2008) salamander case, where he argues that an individual $x$ may fail to be the same person as an individual $\mathrm{y}$ even if $\mathrm{x}$ is both biologically and psychologically continuous with $y$.
} 
aim is to take Markosian's account of what is going on in cases like this and apply it to the Trinity. So, from here forward, I will assume that Markosian is correct about this case, and therefore there are possible cases where some individual $\mathrm{x}$ is the same object as, but not the same person as, some individual $\mathrm{y}$.

How can some $\mathrm{x}$ be the same object as, but not the same person as, some $y$ ? One way to make sense of this is by appealing to Geach's doctrine of relative identity, or something similar, and a number of Trinitarians have gone this route. But Markosian proposes an account of 'identity under a sortal' which he distinguishes from relative identity theories $(2010,137){ }^{8}$ He uses his account to develop a new and improved characterization of the problem of personal identity, which shifts the focus from the persistence of objects that instantiate the property of being a person to the persistence of the instantiations of personhood themselves.

To spell out his view, Markosian introduces three technical terms. First, instances are 'those momentary items, each of which consists of some object's having some property at some instant of time' (ibid, 137). For example, suppose that Tom paints his aunt's fence white at t1. The fence's being white at $\mathrm{t} 1$ is an instance of whiteness.

Second, instantiations are instances as well as their temporally extended cousins', where the temporally extended cousins are composed of instances (ibid, 137). So suppose that after Tom paints the fence, it continues to be white from $\mathrm{t} 1$ through $\mathrm{t} 2$. It's being white at $\mathrm{t} 1$ is both an instance and an instantiation of whiteness, while it's being white from $t 1$ through $t 2$ is an instantiation but not an instance of whiteness. However, the latter instantiation is composed of (infinitely many) instances of whiteness, including the instance at $\mathrm{t} 1$.

\footnotetext{
${ }^{8}$ Though see Baber (2015) on the metaphysical neutrality of relative identity approaches to the Trinity. If she is right about this, then Markosian's view, and my application of it to the Trinity, may actually qualify as an instance of the relative identity approach. Thanks to Aaron Arinder for helpful discussion of relative identity and the Trinity.
} 
Third, episodes are 'instantiations that are maximal in the following sense: instantiation $\mathrm{E}$ of property $\varphi$ is maximal iff the fusion of $\mathrm{E}$ with any further instances of $\varphi$-ness (i.e., one that is not a part of $E$ ) is not a single instantiation of $\varphi$-ness' (ibid, 137). Suppose the fence is painted green at $\mathrm{t} 3$ and then white again at $\mathrm{t} 4$. So, a new instance of whiteness occurs at $\mathrm{t} 4$, separated from the earlier instances by a temporary instantiation of greenness. Will this new instance of whiteness together with the earlier instances of whiteness compose an instantiation of whiteness - one that began back at $\mathrm{t} 1$, was suspended at $\mathrm{t} 3$, and started up again at $\mathrm{t} 4$ ? It's plausible that the answer to this question is no; no single instantiation of whiteness jumps the greenness gap. In that case, the $\mathrm{t} 1-\mathrm{t} 3$ instantiation of whiteness is an episode of whiteness, and the $t 4$ instance of whiteness begins a new episode of whiteness, distinct from the earlier one.

Equipped with the notion of an episode, Markosian formulates the following account of diachronic identity under a sortal: 'To say that some thing, $y$, that is $\varphi$ at $\mathrm{t} 2$ is the same $\varphi$ as some thing, $\mathrm{x}$, that is $\varphi$ at $\mathrm{t} 1$ is to say that $\mathrm{y}^{\prime}$ s being $\varphi$ at $\mathrm{t} 2$ is part of the same episode of $\varphi$-ness as x's being $\varphi$ at $\mathrm{t} 1^{\prime}$ (ibid, 137). He then applies this account to the sortal person and offers a new characterization of the problem of personal identity: it is the problem of identifying the conditions under which an instance of personhood at $\mathrm{t} 1$ is part of the same episode of personhood as an instance of personhood at t2' (ibid, 138).

Markosian uses temporal indices in his account of identity under a sortal because he is interested in the problem of diachronic personal identity. But there is a risk that this will distract us from the fact that, presumably, we can ask of any two or more instances of a sortal property whether they belong to the same episode of that property, even if they are simultaneous, or if we don't know their temporal relationship, or perhaps with some tweaking of Markosian's account - if they are atemporal. ${ }^{9}$

\footnotetext{
${ }^{9}$ We could do this by modifying the definition of 'instance' so that both instantaneous and atemporal instantiations of $\mathrm{P}$ count as instances of $\mathrm{P}$. As for simultaneous instances,
} 
So I propose to reformulate Markosian's account of identity under a sortal as follows. We have seen that any instance has as a constituent an object which instantiates a property. Call that object the instantiator. Then, where E1 and E2 are particular instances of $\varphi$-ness, to say that E1's instantiator is the same $\varphi$ as E2's instantiator is to say that E1 is part of the same episode of $\varphi$-ness as E2. And we can reformulate Markosian's characterization of the problem of personal identity as follows. It is the problem of identifying the conditions under which two or more instances of personhood are part of the same episode of personhood.

Markosian believes that his episodic view of personal identity makes sense of puzzling cases like The Mummy in the following way. Even if there is a single human-shaped object which is first a man, then a mummy, and then a woman, it's not implausible that the instances of personhood which occur at the beginning of the story while the object is a man are not part of the same episode of personhood as the instances of personhood which occur at the end of the story while the object is a woman. But if that's the case, then, by Markosian's account, the woman is not the same person as the man, even if they are the same object.

It's important to be clear that, on Markosian's view, people are not episodes; they are three-dimensional enduring objects. So in cases like The Mummy, where an object is involved in more than one episode of personhood, we should not say, e.g., that a single object participates in multiple people. Instead, we should say something like this: the object at one point in its life fails to be the same person as itself at another point in its life.

This proposal has implications for the apt use of names, predications, descriptions, and so forth. Presumably, the man and woman in the mummy story will go by different names, and we will tend to predicate different properties of them. For example, the woman might go by the name 'Alice' while the man goes by the name 'Bill', and we might say things like 'Alice

Markosian (2004) actually uses his account to make sense of what is going on in certain backward time travel cases. 
is not a man', taking ourselves to be saying something true. But how can we make sense of this if Alice is the same object as - and so numerically identical to - Bill, who seems to be a man?

We can make sense of this by saying that, at least in the cases when people outnumber objects, names for people track the same-person-as relation. An object will have different names associated with its different episodes of personhood, and correctly using one of its names means using it both to refer to that object and using it only when the appropriate episode of personhood is salient. ${ }^{10}$ If names are associated with episodes of personhood in this way, we can understand predications like 'Alice is not a man' as expressing a proposition that is true iff Alice is not the same person as anyone who is a man, i.e., iff the episode of personhood associated with the name 'Alice' is not an episode of personhood during which Alice is a man.

So Markosian's episodic account of identity under a sortal has, among other things, this to recommend it: it makes sense of apparently possible cases where people seem to outnumber objects. But notoriously, the doctrine of the Trinity is also a case where people seem to outnumber objects. So it's time to bring Markosian's proposal to bear on that subject.

\section{An Episodic Model of the Trinity}

I will now present an episodic model of the Trinity that exploits Markosian's account of identity under a sortal. I will build the model out of ideas borrowed from other models of the Trinity in the literature, but recast them in terms of Markosian's metaphysics.

Brian Leftow (2004) has sketched a model of the Trinity on which there is one divine substance that is living three simultaneous or atemporal lives, each of which is the life of a Trinitarian person. This thought can be

\footnotetext{
${ }^{10}$ The idea that names are associated with certain episodes comes from Markosian, who once made the point in lecture, but I do not know whether he would endorse everything I say about it here.
} 
recast in Markosian's terms as follows: God is a single, divine substance that is simultaneously or atemporally participating in three distinct episodes of personhood-those of the Father, Son, and Spirit. That will be the foundational thesis of my episodic model of the Trinity.

One might wonder whether it is possible for the divine substance (or anything else) to participate in multiple episodes of personhood at once. After all, the object in the mummy case only participates in one episode at a time. But imagine that after making the mummy into the woman, the powerful being sends the woman back in time so that she lives for a while alongside the man who is to become the mummy. Then we have one object participating in two episodes of personhood at once.

A critic might press the objection by insisting that the time-traveler can only participate in multiple episodes of personhood at once because she is multilocated - the thought being that distinct episodes of personhood must occur at distinct spatiotemporal locations. Then, if God is outside of space, God can't participate in multiple episodes of personhood. ${ }^{11}$ But it's false that distinct episodes of personhood must occur at distinct spatiotemporal locations. There could be a pair of duplicate ghosts colocated with each other, and then two different episodes of personhood would be occurring in the very same region.

A different worry emerges at this point. In the case of the colocated ghosts, it's clear that there are two episodes of personhood at the relevant region, because there are two objects instantiating personhood at that region. But if the three divine episodes of personhood are each instantiations of the same property (personhood) by the same substance (God), and they do not occur at different times or places, then what individuates them?

\footnotetext{
${ }^{11} \mathrm{It}^{\prime} \mathrm{s}$ possible that something like this thought motivates Effingham's (2015) multilocation model of the Trinity. The time travel case in this paragraph is indebted to Effingham's and Leftow's multilocation and time travel cases, which they use in developing their own models of the Trinity.
} 
One option is to say that the distinctness of instantiations is a brute fact. But even if they have to differ qualitatively in order to be distinct, there is no problem here, for they do not all stand in the same relations. Below I will adapt Swinburne's (1994) model of the divine processessions between the Trinitarian persons for use in the episodic model of the Trinity. Just as Swinburne argues that the divine persons are individuated by their causal interrelationships, so the episodic Trinitarian can say that the three episodes of personhood are individuated by their causal relationships. ${ }^{12}$

I will borrow the next element of the episodic model from Effingham (2015): the divine persons are not the same person because they are not linked by immanent causal relations. His thought is that, given the popular view that immanent causal relations are necessary for personal identity, we can ensure that the divine persons are not the same person by denying that they stand in any such relations. But immanent causal relations hold between stages in the life of an object, and the endurantist takes these stages to be events or, in Markosian's terminology, instantiations (Zimmerman 1997). In that case, it is easy to recast Effingham's idea in terms of Markosian's metaphysics: the three divine episodes of personhood are episodes and not merely instantiations because none of them immanently causes another. ${ }^{13}$

This leads us to another useful idea which has been explicitly endorsed by Moreland and Craig (2005): that God, though a single immaterial substance, has three sets of mental faculties sufficient for personhood. For each episode of personhood occurs in virtue of instantiations of certain psychological properties, such as faculties of thought and volition. But if the episodes of personhood are not immanentcausally linked, then it's natural to think that the instantiations of those

\footnotetext{
${ }^{12}$ See Swinburne (1994), 163-9 and ch. 8, esp. 176-7.

${ }^{13}$ Markosian himself emphasizes that his 'episodic characterization of the problem of personal identity' is compatible with various standard views regarding the conditions on personal identity.
} 
psychological properties are not immanent-causally linked either. And just as the absence of immanent causal relations between instantiations of personhood is sufficient to ensure that the divine persons are not all the same person, so the absence of immanent causal relations between instantiations of these psychological properties is sufficient to ensure that God's mental faculties are not all the same set of mental faculties. Instead, each divine person has their own set of mental faculties. (Similarly, in the mummy case, the woman and the man each have their own set of mental faculties, the woman's having been created by the powerful being when it made her out of the mummy.)

Finally, I will top off the model with an episodic adaptation of Swinburne's (1994) story about the causal relationships between the divine persons. I propose that the Father's episode of personhood occurs simply because God is a divine being, and a divine being is essentially a personal being. By nature, God instantiates whatever psychological properties are necessary for being a person. The Son's episode of personhood occurs because the Father wills that there is an instantiation of personhood by the divine substance which is not immanent-causally linked to the Father's instantiation of personhood. And the Spirit's episode occurs because one or both of these persons will(s) that there is yet another instantiation of personhood by the divine substance which is not connected by immanentcausal relations to either the Father's or the Son's instantiations of personhood. ${ }^{14}$ I leave it open whether these divine volitions are atemporal, simultaneous, or sequential but sempiternal in the way suggested by Swinburne. I also leave it open whether God engages in these volitions contingently or necessarily.

That's the model. I will devote the rest of my space to considering first what I take to be the most serious worry for this model, and then what I take to be its main selling point.

\footnotetext{
${ }^{14}$ Effingham (2018) defends a causal account of the divine processions.
} 
I expect the main worry about the model will be that it entails modalism. Modalism is the heresy which claims that the divine 'persons' are merely different modes of, or roles filled by, a single person, rather than different persons. It's natural to fear that the episodic model falls into this heresy since it claims that the divine persons are numerically identical. ${ }^{15}$

Let's call the Father's episode of personhood F and the instances which compose it the F-instances; call the Son's episode $S$ and the instances which compose it the S-instances; and call the Spirit's episode $\mathrm{H}$ and the instances which compose it the H-instances. Since the very same divine substance features in each of these instances, the instantiator of the Finstances $=$ the instantiator of the S-instances $=$ the instantiator of the $\mathrm{H}$ instances. And that sounds like modalism. ${ }^{16}$

But recall (my formulation of) Markosian's account of identity under a sortal: where E1 and E2 are particular instances of $\varphi$-ness, to say that E1's instantiator is the same $\varphi$ as E2's instantiator is to say that E1 is part of the same episode of $\varphi$-ness as E2. Apply this to the episodic model of the Trinity. To say that the instantiator of the F-instances is the same person as the instantiator of the S-instances (for example) is to say that the F-instances are part of the same episode of personhood as the S-instances. But they're not. The F-instances compose one episode of personhood, the S-instances another, and the H-instances yet another. So, if Markosian's episodic view of personal identity is right, the model is not modalist.

A critic might think this is a shallow victory, because even if the model is not technically modalist, it cannot make sense of standard Trinitarian claims that predicate different properties of the divine persons, like 'The Son became incarnate but the Father and Spirit did not'. For even

\footnotetext{
${ }^{15}$ Likewise, defenders of other models of the Trinity which either identify the divine persons with each other or have been interpreted as doing so have felt a special burden to show that their models are not modalist: see Leftow (2004) and Effingham (2015).

${ }^{16}$ Remember the quote from Hasker (2013), 116, in my opening paragraph.
} 
if the model is not technically modalist, one might think that this sentence expresses something that is not merely incompatible with modalism, but also incompatible with the position that the divine persons are numerically identical. After all, it predicates different properties of the divine persons, and so, by the indiscernibility of identicals, they are numerically distinct. ${ }^{17}$

My response to this objection begins with the observation that the exact nature of the unusual unity between the divine persons has always been unclear. The creeds tell us certain things about the unity of the persons, such as that they share the same divine nature, and that, while each is God, there is just one God. But Christians have usually admitted that this doctrine is deeply mysterious, and those who have explored this mystery have disagreed both about how the creedal claims should be interpreted, and what metaphysical details might undergird them.

In light of these observations, I think it is unlikely that the sentence 'The Son became incarnate but the Father and Spirit did not', in ordinary Trinitarian usage, expresses something metaphysically nuanced enough to be incompatible with the episodic model of the Trinity. More likely, it expresses something with a fair amount of metaphysical neutrality something that would be true given any of a range of the proposed Trinitarian models, perhaps including models on which the persons are different persons and yet numerically identical.

This opens up space for the episodic Trinitarian to suggest that these sentences have the following truth conditions. Recall the way we approached sentences like 'Alice is not a man'. We noted that, at least in cases when people outnumber objects, names for people track the sameperson-as relation, meaning that an object will have different names associated with its different episodes of personhood. When it comes to the Trinity, the names 'the Father', 'the Son', and 'the Spirit' will be associated with episodes $\mathrm{F}, \mathrm{S}$, and $\mathrm{H}$, respectively. If that's right, we can understand predications like 'The Son became incarnate but the Father and Spirit did

\footnotetext{
${ }^{17}$ That the Father and Son must be distinct because they have different properties is a point often emphasized by Dale Tuggy.
} 
not' as expressing a proposition that is true iff the Son, but not the Father or Spirit, is the same person as someone who is incarnate, i.e., iff the episode of personhood associated with the name 'the Son', but not those associated with the names 'The Father' or 'the Spirit', is an episode of personhood during which God is incarnate.

Of course, nothing can literally occur during one episode and not the others, since they are either simultaneous or atemporal. But there is a way around this glitch. We have seen that each divine episode of personhood occurs in virtue of a different set of divine mental faculties. And God will have some properties - like the property of becoming incarnate - in virtue of the activity of one set of mental faculties and not the others. Therefore, I propose that we revise our account of having a property $\mathrm{P}$ during an episode E such that a subject $S^{\prime}$ s having $P$ during $E$ is shorthand for the claim that $S^{\prime}$ s having $\mathrm{P}$ and E's occurring obtain in virtue of facts about the same set of mental faculties.

So I think the main worry facing this model - that it entails modalism - can be defused. What about its main virtue?

\section{$5 \quad$ Solving the Puzzles}

By my lights, the main virtue of this model is how nicely it handles familiar puzzles about the Trinity. In this section, I will argue that it solves three such puzzles.

\subsection{First Puzzle: The Logical Problem of the Trinity}

Consider first the well-worn 'logical problem of the Trinity', so named by Cartwright (1990), which is sometimes formulated as an inconsistent triad:

1. There is one God.

2. There are three divine persons.

3. Every divine person is God. 
The doctrine of the Trinity entails that each of these claims is true, but their conjunction appears to be logically inconsistent. However, I will argue that the episodic model of the Trinity dissolves this problem.

Let's take 'God' to name a substance that instantiates deity, and let's take (1) and (3) at face value: there is one substance that instantiates deity, and every divine person is numerically identical to that substance. All of this is true on the episodic model. Does it follow that there are not three divine persons? That depends on how we should count people on Markosian's view.

I think that how we should count depends on what sortal we are interested in. If we really want to know how many objects there are, then we should count by the ordinary identity relation. ${ }^{18}$ But if we want to know how many people there are, then we have to play by the rules of the relevant sortal. We should count by identity under the person sortal. So, where an object in one part of its life fails to stand in the same-person-as relation to itself in another part of its life, we should count two people, despite the fact that we would also count just one object. In cases of this sort, counting people by the counting rules appropriate to the person sortal requires us, in effect, to double-count (or triple-count, etc.) objects by the counting rules appropriate to the object sortal.

To illustrate this counting procedure, consider the Mummy case. In that case, we have an object which participates in an episode of personhood at an earlier interval when it is a man, and then participates in a second episode of personhood at a later interval when it is a woman. Therefore it fails to stand in the same-person-as relation to itself across the two intervals. So, counting by the same-person-as relation, there are two people in the course of this story.

\footnotetext{
${ }^{18}$ I borrow the talk of 'counting by identity' vs. other ways of counting from Brower and Rea (2005), who distinguish counting by identity from counting by numerical sameness. And following Rea (2009b), I take it that identity under the sortal object just is the ordinary identity relation.
} 
Now imagine for a moment that God also participates in multiple episodes of personhood sequentially: first there is an interval during which God participates in the Father's episode of personhood; then, after a relevant causal discontinuity which ends the Father's episode, there is a later interval during which God participates in the Son's episode; which is in turn followed by the Spirit's episode. As in the Mummy case, God fails to be the same person as Godself across these intervals associated with each episode. So, counting by the same-person-as relation, there are three divine persons in the course of this story.

And since it is the fact that the episodes are different episodes, and not their sequential relationship, that is doing the crucial work, we should still count three people if we imagine that the episodes are not sequential after all, but rather simultaneous or atemporal (something which I have already argued is possible). So, even though the divine persons are numerically identical as (1) and (3) imply, when we count them in the way appropriate to the person sortal, we count three of them.

\subsection{Second Puzzle: The Problem of Triunity}

Let's consider a second puzzle - one that I dubbed the 'Problem of Triunity' (Mooney 2018), because it centres on the property of triunity, which God seems to have but which the persons individually do not seem to have. Once again, the puzzle is an inconsistent triad:

1. God is triune.

2. The Son is God.

3. The Son is not triune.

$(2018,2)$. Any of the divine persons could be substituted for the Son to generate the puzzle. Whichever person we plug in, the resulting propositions will be jointly inconsistent, and so at least one of the claims in the triad must be false. The problem is that Trinitarians often affirm (1) and (2), and they seem disposed to affirm (3) as well. 
But for the episodic Trinitarian, saying 'The Son is not triune' is like saying, in the mummy case, 'Alice is not two people'. Imagine that Alice travels back in time to exist alongside the man she once was. At that time, strictly speaking, Alice is two people, since Alice is an object participating in two episodes of personhood. But since the name 'Alice' is associated with just one of those episodes, 'Alice is not two people' will ordinarily express a proposition that is true iff Alice is not the same person as anyone who is two people, i.e., iff the episode of personhood associated with the name 'Alice' is not an episode of personhood during which she is two people. On the revised account of what it is to have a property during an episode of personhood, introduced in the section on modalism, this will be so iff it is not the case that the episode associated with the name 'Alice' obtains in virtue of facts about both the woman's and man's sets of cognitive faculties. Since it does not, Alice is not the same person as anyone who is two people. Similarly for (3). Strictly speaking, the Son is triune, since the Son is the divine substance that participates in three distinct episodes of personhood at once. But since the name 'the Son' is associated with a certain episode of personhood, 'the Son is not triune' will normally express a proposition that is true iff the Son is not the same person as anyone who is triune, i.e., iff the episode of personhood associated with the name 'the Son' is not an episode of personhood during which the Son is triune. Given the revised account of what it is to have a property 'during' an episode of personhood, the divine substance is triune during one of its episodes of personhood iff that episode occurs in virtue of facts about all three divine sets of mental faculties. Since there is no such episode, the Son is not the same person as anyone who is triune.

So, strictly speaking, the Son is triune and yet the Son is not the same person as anyone who is triune, and the expression 'the Son is not triune' often expresses the latter proposition. When it does, it expresses a proposition that is both true and consistent with the conjunction of (1) and (2).

But is that enough? Let personal triunity be the property of being the same person as someone who is triune. In my (2018) I argued that triunity 
is an essential divine attribute, and so the Son must be triune to qualify as divine (3-7). A critic might suggest that personal triunity is also an essential divine attribute, and so the Son must not only be triune, but also the same person as someone who is triune, to qualify as divine. In defence of this claim, our critic might say that my reasons for thinking that triunity is an essential divine attribute carry over to personal triunity.

But as it turns out, they don't. Let's consider each in turn. First, I observed in the earlier article that triunity is similar to paradigmatic divine attributes in that, e.g., it is one of God's essential properties. But personal triunity is not one of God's essential properties, for the simple reason that it is not a property that God has at all. God has personal triunity iff the expression 'God is the same person as someone who is triune' expresses something true. And that expression is true iff God participates in an episode of personhood during which someone is triune. But we have already observed that there is no such episode. So God does not instantiate personal triunity.

Second, I argued in the earlier article that triunity's being an essential divine attribute explains why God is triune. But again, there is no parallel reason to think that personal triunity is an essential divine attribute, since God doesn't instantiate personal triunity. If God doesn't have the property, we don't need to explain why God has it.

Third, I contended that triunity is a great-making property, and any great-making property is an essential divine attribute. ${ }^{19}$ Is personal triunity also a great-making property, and so also an essential divine attribute? It's hard to see why it would be. Having personal triunity entails having valuable personal and interpersonal properties, but triunity alone seems to be sufficient to secure properties of that sort. So it is not clear that adding personal triunity on top of triunity would make any difference in overall greatness.

19 Actually, I allowed for exceptions in cases where great-making properties are not possible or not compossible, but that isn't relevant to the present discussion. 
As far as I can see, the episodic Trinitarian does not need to concede that personal triunity is an essential divine attribute, and so she does not need to say that the Son has that property. But she can and should say that the Son has triunity, for she has a promising way to deny (3) in the sense that makes it inconsistent with (1) and (2), thereby dissolving the puzzle.

\subsection{Third Puzzle: A Problem about the Processions}

Let's consider one more puzzle. The recent literature has seen increased discussion of the divine processions (e.g. Mullins 2017, Hasker 2017, Effingham 2018, Makin 2018). Much of the discussion is focused on a problem having to do with divine aseity. If God has the property of aseity, then God cannot causally or metaphysically depend on anything. But it's hard to make sense of the notion that the Son is begotten by the Father without understanding this as involving some kind of causal or metaphysical dependence of the Son on the Father (Mullins 2017). Since the Son is God, this creates a problem, which can again be formulated as an inconsistent triad:

1. God is not begotten.

2. The Son is God.

3. The Son is begotten.

A similar puzzle can be constructed around the spiration of the Holy Spirit. But once again, I think the episodic model of the Trinity solves this puzzle.

To see how, let's return one more time to the mummy case. We've seen that when the powerful being takes the mummy and turns it into a woman, the being has not created a new object. But it has caused that object to be a person that is not the same person as it was before, when it was a man. So, the woman does not depend either causally or metaphysically on the actions of the powerful being for her existence, but she does depend causally on the actions of the powerful being for being a person who is a different person than the man. 
I think we can say the same about the Son. Since the Son is identical to God, and God does not depend either causally or metaphysically on anything for God's existence, the Son does not depend either causally or metaphysically on anything for the Son's existence. But the Son does depend causally on the Father for being a person who is a different person than the Father. The episodic Trinitarian can suggest that this is what it means for the Son to be begotten of the Father.

And that gives her a strategy for solving the puzzle about the processions. For the set of propositions in the triad to be jointly inconsistent, we must read (1) as expressing a proposition which is true iff God is not identical to some substance that is begotten. But if we do read it that way, then (1) is false. For God is a substance that is identical to the Son, and the Son is begotten. And we have just seen that being begotten does not imply failing to have the property of aseity, since it is not about depending either causally or metaphysically on something else for one's existence. So denying (1) turns out to be unproblematic after all.

By similar reasoning, we can show that God is a substance that is identical to the Spirit, and so God is spirated, and yet God still has the property of aseity. God both begets and spirates Godself. Even so, for reasons that are by now familiar, only the Son is the same person as the divine person who is begotten, and only the Spirit is the same person as the divine person who is spirated.

One could object that my understanding of aseity is too weak. Perhaps aseity is not merely independence with respect to one's existence, but rather independence with respect to all of one's properties, or all of one's intrinsic properties, or etc. Then the episodic model of begetting and spirating that I just proposed will run afoul of our suitably strengthened account of aseity, for the causal dependence of some of the divine persons on others entails that God is causally dependent with respect to properties like being triune.

My response to this objection is that, however we analyse aseity, our analysis should not have the consequence that God cannot depend on Godself for God's properties. Intuitively, if there is any difference between 
self-dependence and independence, it is not a difference which threatens God's aseity or God's perfection more generally. Presumably this is why God's aseity is often characterized, not as independence simpliciter, but as independence of everything distinct from God (e.g. Brower (2009)). And since the episodic model entails that the divine persons are numerically identical to God, causal dependence of one divine person on another in some respect turns out to be a case of God depending on Godself in that respect. Aseity is preserved.

\section{Conclusion}

By using Markosian's episodic account of identity under a sortal, and his application of that account to the person sortal in particular, we can construct a model of the Trinity which vindicates the minority position that the divine persons can be numerically identical without being the same person. Moreover, I've argued that the model solves at least three problems for the doctrine of the Trinity that have been discussed in the literature: the logical problem of the Trinity, the problem of Triunity, and a problem about the divine processions. So, the model seems to have a lot going for it. At the very least, it should prove attractive to those with certain metaphysical sensibilities. ${ }^{20}$

\section{References}

BABER, H. E. (2015). 'The Trinity: Relative Identity Redux', Faith and Philosophy, 32, 161-171.

BAKER, LyNNE RUdDER (2000). Persons and Bodies (Cambridge: Cambridge University Press).

\footnotetext{
${ }^{20}$ My thanks to Aaron Arinder, Joseph Jedwab, an audience at the 2019 midwest regional meeting of the Society of Christian Philosophers, and to various referees for comments on this paper or an ancestor of this paper.
} 
BROWER, JEFFREY (2009). 'Simplicity and Aseity', in T. Flint and M. Rea, eds., The Oxford Handbook of Philosophical Theology (Oxford: Oxford University Press), 105-128.

BROWER, JEFFREY and MiCHAEL REA (2005). 'Material Constitution and the Trinity', Faith and Philosophy, 22, 57-76.

CARTWRIGHT, Richard (1990). 'On the Logical Problem of the Trinity', in Philosophical Essays (Cambridge MA: MIT Press), 187-200.

EFFINGHAM, NIKK (2015). "Multiple Location and Christian Philosophical Theology." Faith and Philosophy 32, 25-44.

EFFINGHAM, NiKK (2018). 'The Philosophy of Filioque', Religious Studies, 54, 297-312.

HASKER, WILLIAM (2014). Metaphysics and the Tri-Personal God (Oxford: Oxford University Press).

HASKER, William (2017). 'God's Only Begotten Son: A Reply to Mullins', European Journal for Philosophy of Religion, 9, 217-237.

KLEINSCHMIDT, SHIEVA (2016). 'Simple Trinitarianism and Feature-Placing Sentences', Faith and Philosophy, 33, 257-277.

KLEINSCHMIDT, SHIEVA (2018). 'Simple Trinitarianism and Empty Names', Religious Studies 54, 325-335.

LEFTOW, BRIAN (1999). 'Anti Social Trinitarianism', in S. Davies, D. Kendall, and G. O'Collins (eds.), The Trinity: An Interdisciplinary Symposium (Oxford: Oxford University Press), 203-249.

LEFTOW, BRIAN (2004). 'A Latin Trinity', Faith and Philosophy, 21, 304-333.

LEFTOW, BRIAN (2007). 'Modes Without Modalism', in P. van Inwagen and D. Zimmerman (eds.), Persons: Human and Divine (Oxford: Oxford University Press), 357-375.

MAKIN, MARK (2018). 'God from God: The Essential Dependence Model of Eternal Generation.' Religious Studies, 54, 377-394.

MARKOSIAN, NED (2010). 'Identifying the Problem of Personal Identity', in J. Campbell, M. O'Rourke, and H. Silverstein (eds.), Time and Identity (MIT Press), 129-148.

MARKOSIAN, NeD (2008). ‘Three Problems for Olsen's Account of Personal Identity', Abstracta 3, 16-22. 
MARKOSIAN, NED (2004). 'Two Arguments from Sider's Four Dimensionalism', Philosophy and Phenomenological Research, 68, 665673.

MoOney, Justin (2018). 'A New Logical Problem for the Doctrine of the Trinity', Religious Studies, 54, 1-13.

MUlLINS, RYAN, T. (2017). 'Hasker on the Divine Processions of the Trinitarian Persons', European Journal for Philosophy of Religion 9, 181216.

OLSON, ERIC (1997). The Human Animal, (Oxford: Oxford University Press).

ReA, Michael C. (2009a). 'The Trinity', in T. Flint and M. Rea (eds.), The Oxford Handbook of Philosophical Theology (Oxford: Oxford University Press), 403-429.

REA, MiCHAEL C. (2009b). 'Relative Identity and the Doctrine of the Trinity', in T. McCall and M. Rea (eds.), Philosophical and Theological Essays on the Trinity (Oxford: Oxford University Press), 249-262.

SWINBURNE, RICHARD (1994). The Christian God (Oxford: Oxford University Press).

ZIMMERMAN, DEAN (1997). 'Immanent Causation', Philosophical Perspectives 11, 433-471. 